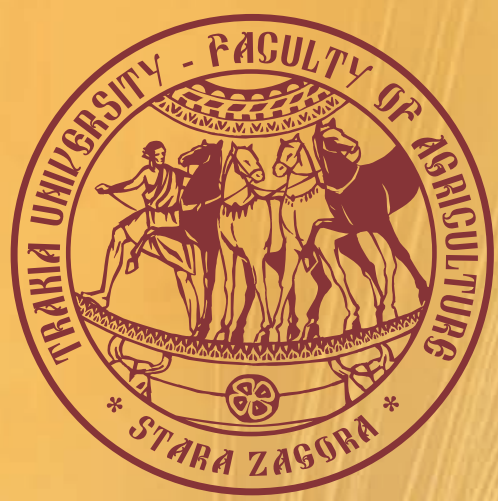

ISSN $1313-8820$ (print)

ISSN $1314-412 X$ (online)

Volume 8 , Number 4

December 2016

\title{
AGRICULTURAL
}

\section{SCIENCE AND TECHNOLOGY}

\section{6}

An International Journal Published by Faculty of Agriculture, Trakia University, Stara Zagora, Bulgaria 


\section{Editor-in-Chief}

Georgi Petkov

Faculty of Agriculture

Trakia University, Stara Zagora

Bulgaria

\section{Co-Editor-in-Chief}

Dimitar Panayotov

Faculty of Agriculture

Trakia University, Stara Zagora

Bulgaria

\section{Editors and Sections}

\section{Genetics and Breeding}

Tsanko Yablanski (Bulgaria)

Atanas Atanasov (Bulgaria)

Nikolay Tsenov (Bulgaria)

Max Rothschild (USA)

Ihsan Soysal (Turkey)

Horia Grosu (Romania)

Bojin Bojinov (Bulgaria)

Stoicho Metodiev (Bulgaria)

Svetlana Georgieva (Bulgaria)

\section{Nutrition and Physiology}

Nikolai Todorov (Bulgaria)

Peter Surai (UK)

Zervas Georgios (Greece)

Ivan Varlyakov (Bulgaria)

\section{Production Systems}

Radoslav Slavov (Bulgaria)

Dimitar Pavlov (Bulgaria)

Bogdan Szostak (Poland)

Banko Banev (Bulgaria)

Georgy Zhelyazkov (Bulgaria)

\section{Agriculture and Environment}

Ramesh Kanwar (USA)

Martin Banov (Bulgaria)

Peter Cornish (Australia)

\section{Product Quality and Safety}

Marin Kabakchiev (Bulgaria)

Stefan Denev (Bulgaria)

Vasil Atanasov (Bulgaria)

Roumiana Tsenkova (Japan)

\section{English Editor}

Yanka Ivanova (Bulgaria)
Scope and policy of the journal Agricultural Science and Technology /AST/ - an International Scientific Journal of Agricultural and Technology Sciences is published in English in one volume of 4 issues per year, as a printed journal and in electronic form. The policy of the journal is to publish original papers, reviews and short communications covering the aspects of agriculture related with life sciences and modern technologies. It will offer opportunities to address the global needs relating to food and environment, health, exploit the technology to provide innovative products and sustainable development. Papers will be considered in aspects of both fundamental and applied science in the areas of Genetics and Breeding, Nutrition and Physiology, Production Systems, Agriculture and Environment and Product Quality and Safety. Other categories closely related to the above topics could be considered by the editors. The detailed information of the journal is available at the website. Proceedings of scientific meetings and conference reports will be considered for special issues.

\section{Submission of Manuscripts}

All manuscripts written in English should be submitted as MS-Word file attachments via e-mail to editoffice@agriscitech.eu. Manuscripts must be prepared strictly in accordance with the detailed instructions for authors at the website

www.agriscitech.eu and the instructions on the last page of the journal. For each manuscript the signatures of all authors are needed confirming their consent to publish it and to nominate on author for correspondence.

They have to be presented by a submission letter signed by all authors. The form of the submission letter is available upon from request from the Technical Assistance or could be downloaded from the website of the journal. Manuscripts submitted to this journal are considered if they have submitted only to it, they have not been published already, nor are they under consideration for publication in press elsewhere. All manuscripts are subject to editorial review and the editors reserve the right to improve style and return the paper for rewriting to the authors, if necessary. The editorial board reserves rights to reject manuscripts based on priorities and space availability in the journal.

The journal is committed to respect high standards of ethics in the editing and reviewing process and malpractice statement. Commitments of authors related to authorship are also very important for a high standard of ethics and publishing. We follow closely the Committee on Publication Ethics (COPE), http://publicationethics.org/resources/guid $\underline{\text { elines }}$

The articles appearing in this journal are indexed and abstracted in: DOI, EBSCO Publishing Inc. and AGRIS (FAO).

The journal is accepted to be indexed with the support of a project № BG051P00013.3.05-0001 "Science and business" financed by Operational Programme "Human Resources Development" of EU. The title has been suggested to be included in SCOPUS (Elsevier) and Electronic Journals Submission Form (Thomson Reuters).

\section{Address of Editorial office:}

Agricultural Science and Technology Faculty of Agriculture, Trakia University Student's campus, 6000 Stara Zagora Bulgaria

Telephone.: +35942699330 $+35942699446$

www.agriscitech.eu

\section{Technical Assistance:}

Nely Tsvetanova

Telephone.: +35942699446

E-mail: editoffice@agriscitech.eu 


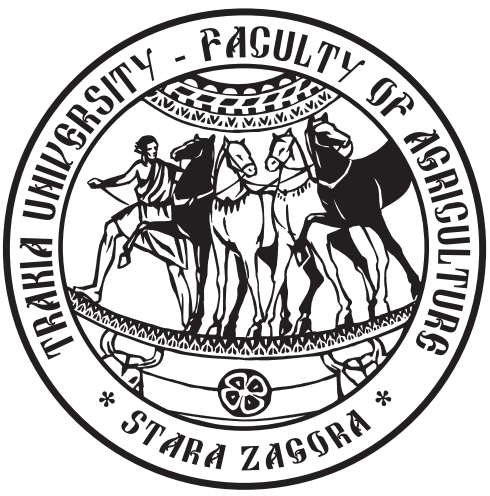

AGRICULTURAL

SCIENCE AND TECHNOLOGY

\section{6}

An International Journal Published by Faculty of Agriculture,

Trakia University, Stara Zagora, Bulgaria 


\title{
Genetics and Breeding
}

\section{Productivity performance of bread winter wheat genotypes of local and foreign origin}

\author{
G. Raykov*, P. Chamurliyski ${ }^{1}$ S. Doneva', E. Penchev ${ }^{1}$, N. Tsenov² \\ 'Dobrudzha Agricultural Institute, 9520 General Toshevo, Bulgaria \\ ${ }^{2}$ Agronom I Holding, 9300 Dobrich, Bulgaria
}

(Manuscript received 12 October 2015; accepted for publication 18 October 2016)

\begin{abstract}
The proper choice of parental forms is the basis for developing superior varieties with valuable agronomic properties. A priority in modern breeding is increased productivity. The aim of this study was to establish the relative contribution of the yield traits to the productivity of common wheat accessions of different geographical origin. The trial was conducted during 2012 - 2014 at Dobrudzha Agricultural Institute, General Toshevo. The study included 118 varieties and lines originating from Europe, Asia and North America. The tested materials were grown in a randomized block design in three replications, the plot size being $7.5 \mathrm{~m}^{2}$. Six cultivars were used as standards: Aglika, Pobeda, Enola, Sadovo 1, Antonovka and Pryaspa. Number of grains per spike, number of grains per $m^{2}$ and thousand kernel weight had the highest positive influence on grain yield. The highest levels of productivity were reported in cultivars PKB Vizelika, PKB Rodika, Joana and Midas averaged for the two years of the study, cultivar Vizelika with origin from PKB - Serbia realizing a yield of 9.03 t.ha ${ }^{-1}$. Despite environmental effect and interaction, significant genotypic modality on the investigated traits was observed and analysed. All studied accessions can be successfully included in a breeding program to increase productivity.
\end{abstract}

Keywords: Triticum aestivum L., new varieties, grain yield, yield components

Abbreviations: GY - grain yield, TKW - thousand kernel weight, NPT - number of productive tillers per $\mathrm{m}^{2}$, DTH - days to heading, as number from $1^{\text {st }}$ January, $\mathrm{SH}$ - stem height, NGS-number of grains per spike, NGM - number of grains per $\mathrm{m}^{2}$.

\section{Introduction}

Wheat is a main crop and human food due to its specific properties and wide area of cultivation. In contrast to other field crops, it has typically low ecological plasticity, which imposes the necessity of developing varieties adapted to specific agroecological regions (Tsenov et al., 2009). A genetic distance between the parental components of wheat (Triticum aestivum L.) is required to develop better genetic combinations in today's breeding. Since crosses are made between lines with similar agronomic and biological characteristics, it is necessary to study them in detail to reduce the potential risk of undesirable narrowing of the basis of the used germplasm (Huang et al., 2007; Chen et al., 1994). The success of any breeding program is based on a wide genetic variability of forms from local and foreign origin and on the thorough and detailed investigation of this variability as well as developing new approaches to evaluate grain production (Stoeva et al., 2009; Reynolds et al., 2009). The quantitative traits of productivity play an important role in the evaluation of a given accession (Tsenov et al., 2014; Slafer et al., 2014). It is also important to know to what extent they vary under specific growing environments. Such investigations are significant for determining the agronomic and breeding value of the accessions. In constant effort to reduce trade-offs between traits, breeders have altered their expression to achieve high yields. Some authors find grain yield (GY) increase to be accommodated by increase of number of grains per spike (NGS) and number of productive tillers per $\mathrm{m}^{2}$ (NPT) (Sanchez-Garcia et al., 2013; Okuyama et al., 2004). Others have concluded that increase in GY * e-mail: georgi.raikov.dzi@gmail.com can be achieved by combination of number of grains per $\mathrm{m}^{2}$ (NGM) and thousand kernel weight (TGW) (Bustos et al., 2013). The investigated cultivars construct their GY on significantly different combination of productivity components which present opportunity to be evaluated under the conditions of South Dobrudzha.

\section{Material and methods}

The investigation was carried out at Dobrudzha Agricultural Institute (DAI), General Toshevo under field conditions during 20122014. Grain yield and the components of productivity of 118 common winter wheat (Triticum aestivum L.) accessions of different geographical origin were investigated. Nine main groups of accessions have been included: Bulgaria - 32; Russia - 13; Hungary - 13; Serbia - 11; Ukraine -10; Romania - 9; USA - 9; Moldova - 8; Western Europe- 13 (Czech Republic - 6; France -4; Austria-3)

The breeding materials were grown as a randomized block design in three replications, the plot size being $7.5 \mathrm{~m}^{2}$. The following traits were analysed: GY, thousand grain weight (TKW), number of productive tillers per $\mathrm{m}^{2}$ (NPT), date to heading (DTH), stem height $(\mathrm{SH})$, number of grains per spike (NGS) and number of grains per $\mathrm{m}^{2}$ (NGM).

Analysis of variation was done to determine main effects. Correlation analysis by Pearson was done in order to find out what the interconnection between structural elements and productivity. 
For statistical analysis of the obtained results, the programs XLSTAT-Pro 7.5.2 and Microsoft Excel 2003 were used.

\section{Results and discussion}

Analysis of the variances of all investigated traits was performed to determine main effects and interaction (Table 1). Results show high level of significance within effects. GY and TGW was highly dependant on the environment factor with $66.57 \%$ $(p<0.0001)$ and $63.78 \%(p<0.0001)$ variation accounting for it. Such observations are not an exception due to the field conditions of the experiment. All other investigated traits demonstrated dominance of the effect of genotype over their value.

Days to heading, as number from $1^{\text {st }}$ January (DTH) and stem height $(\mathrm{SH})$ traits were the most conservative $-75.74 \%(p<0.0001)$ and $70.86 \%(p<0.0001)$ of their variation accounted for the wide genetic variability of Genotype. Characters NPT and NGS show predominance of genotypic variability with high interaction with the environment factor. All elements of productivity, including GY show significant interaction of genotype with the environment; the highest one being in the case of NGM with $20.2 \% ; p<0.0001$. To analyse this effect in depth further studies are needed (Zobel et al., 1988).

Table 1. ANOVA of the investigated traits

\begin{tabular}{|c|c|c|c|c|}
\hline Traits & Factor & MS & $p$-value & SS. $\%$ \\
\hline & Genotype & 4.1 & $<0.0001$ & 14.53 \\
\hline \multirow[t]{3}{*}{ GY } & Environment & 2258.8 & $<0.0001$ & 66.57 \\
\hline & GxE & 2.9 & $<0.0001$ & 9.94 \\
\hline & Genotype & 96.1 & $<0.0001$ & 25.89 \\
\hline \multirow[t]{3}{*}{ TKW } & Environment & 27688.4 & $<0.0001$ & 63.78 \\
\hline & GxE & 35.7 & $<0.0001$ & 9.61 \\
\hline & Genotype & 31018.7 & $<0.0001$ & 38.36 \\
\hline \multirow[t]{3}{*}{ NPT } & Environment & 318050.9 & $<0.0001$ & 3.36 \\
\hline & GxE & 12238.7 & 0.0064 & 15.14 \\
\hline & Genotype & 54705 & $<0.0001$ & 70.86 \\
\hline \multirow[t]{3}{*}{$\mathrm{SH}$} & Environment & 11272.1 & $<0.0001$ & 14.6 \\
\hline & GxE & 7040.4 & $<0.0001$ & 9.12 \\
\hline & Genotype & 41.1 & $<0.0001$ & 75.72 \\
\hline \multirow[t]{3}{*}{ DTH } & Environment & 865.9 & $<0.0001$ & 13.64 \\
\hline & GxE & 5.2 & $<0.0001$ & 9.57 \\
\hline & Genotype & $2.81 * 10^{9}$ & $<0.0001$ & 35.06 \\
\hline \multirow[t]{3}{*}{ NGM } & Environment & $1.85^{*} 10^{9}$ & $<0.0001$ & 23.14 \\
\hline & GxE & $1.62 * 10^{9}$ & $<0.0001$ & 20.2 \\
\hline & Genotype & 82.2 & $<0.0001$ & 44.91 \\
\hline \multirow[t]{2}{*}{ NGS } & Environment & 1343.1 & $<0.0001$ & 6.27 \\
\hline & GxE & 25.9 & 0.00015 & 14.16 \\
\hline
\end{tabular}

Table 2. Pearson correlations between GY and its components

\begin{tabular}{|c|c|c|c|c|c|c|}
\hline Traits & DTH & SH & NPT & TKW & NGS & NGM \\
\hline$\overline{\mathrm{SH}}$ & $0.313^{*}$ & & & & & \\
\hline$p$-value & 0.001 & & & & & \\
\hline NPT & -0.019 & 0.074 & & & & \\
\hline $\mathrm{p}$-value & 0.839 & 0.427 & & & & \\
\hline TKW & -0.128 & -0.03 & $-0.353^{*}$ & & & \\
\hline$p$-value & 0.168 & 0.746 & $<0.0001$ & & & \\
\hline NGS & -0.096 & $-0.38^{*}$ & $-0.619^{*}$ & -0.003 & & \\
\hline$p$-value & 0.3 & $<0.0001$ & $<0.0001$ & 0.977 & & \\
\hline NGM & -0.151 & $-0.403^{*}$ & $0.191^{*}$ & $-0.362^{*}$ & $0.594^{*}$ & \\
\hline $\mathrm{p}$-value & 0.103 & $<0.0001$ & 0.038 & $<0.0001$ & $<0.0001$ & \\
\hline GY & $-0.25^{*}$ & $-0.392^{*}$ & -0.096 & $0.49^{*}$ & $0.544^{*}$ & $0.63^{*}$ \\
\hline $\mathrm{p}$-value & 0.006 & $<0.0001$ & 0.302 & $<0.0001$ & $<0.0001$ & $<0.0001$ \\
\hline
\end{tabular}

* Values are significant at level alpha $=0.05$ 
All correlations between the elements of productivity and grain yield are shown in Table 2. The highest significant contribution to grain yield in the investigated genotypes had NGM; however, it is apparent that other traits have contributed to the GY of the investigated accessions and different combinations of $\mathrm{SH}, \mathrm{DTH}$, NGS and TKW was involved in rise of productivity. Despite insignificant negative correlation with GY, NPT has significant positive effect on many other traits, including NGM (Donmez et al., 2001). DTH and SH are negatively correlated with GY (Table 2), which suggests increase in date to heading and stem height would result in reduction of GY. Two yield components, NPT and NGS, were associated with gain in grain yield in most of the genotypes, both traits contributed to increase in NGM, as yields advanced moreover in semi-dwarf accessions with shorter DTH period. Negative correlations between NPT, NGS and TKW was observed; however, this can be considered an expression of regularity since they entirely confirm previous investigations on winter bread wheat (Okuyama etal., 2004; Tsenov et al., 2015).

Accessions yielding $10 \%$ or higher from the standard variety are shown in Table 3. ANOVA was carried out on the factors investigated

Table 3. Mean values of productivity and yield components

\begin{tabular}{|c|c|c|c|c|c|c|c|}
\hline Varieties, Origin & DTH & $\mathrm{SH}, \mathrm{cm}$ & NPT & TKW & NGS & NGM & GY, tha $a^{-1}$ \\
\hline PKB Vizelika, Serbia & 129 & $96.0^{* *(-)}$ & 616 & $40.0^{\text {ns }}$ & $36.3^{* *}$ & $22541^{* *}$ & $9.03^{* *}$ \\
\hline PKB Rodika, Serbia & 130 & $87.3^{* * *(-)}$ & 650 & $38.6^{*(-)}$ & $34.8^{*}$ & $23172^{\star * *}$ & $8.94^{*}$ \\
\hline Joana, Bulgaria & 128 & $89.2^{* * *(-)}$ & 663 & $42.6^{*}$ & 30.9 & $20913^{*}$ & $8.91^{*}$ \\
\hline Midas, Austria & 139 & $113.8^{* * *}$ & 769 & $41.6^{\text {ns }}$ & 28.5 & $21094^{*}$ & $8.77^{*}$ \\
\hline Azimut, France & 130 & $92.7^{* * *(-)}$ & 758 & $40.5^{\mathrm{ns}}$ & 28.1 & $21286^{*}$ & $8.61^{*}$ \\
\hline F05190 GP-1, Romania & 129 & $97.8^{*(-)}$ & 693 & $40.1^{\text {ns }}$ & 31.1 & $21304^{*}$ & $8.54^{\mathrm{ns}}$ \\
\hline GK Csillag, Hungary & 131 & $91.2^{* * *(-)}$ & 727 & $35.3^{* * *(-)}$ & $32.7^{*}$ & $23918^{* * *}$ & $8.43^{\text {ns }}$ \\
\hline Kantata, Serbia & 132 & 103.3 & 737 & $37.7^{* * *(-)}$ & 30.2 & $22352^{* *}$ & 8.43 \\
\hline Litera, Romania & 129 & $95.5^{* * *(-)}$ & 787 & $38.1^{* * *(-)}$ & 28.6 & $22077^{\star *}$ & 8.41 \\
\hline Grom, Russia & 132 & $95.0^{* * *(-)}$ & 632 & $36.9^{* * *(-)}$ & $34.3^{*}$ & $22777^{\star \star}$ & 8.4 \\
\hline Glosa, Romania & 129 & $97.3^{* *(-)}$ & 745 & $42.6^{*}$ & 26.6 & 19564 & 8.34 \\
\hline Zlatina, Bulgaria & 131 & 106.3 & 632 & $43.1^{* *}$ & 30.3 & 19185 & 8.27 \\
\hline Koprinka, Bulgaria & 133 & 100.3 & 669 & $44.1^{* * *}$ & 27.1 & 18714 & 8.26 \\
\hline Jumna, Russia & 129 & $90.7^{* * *(-)}$ & 597 & $40.8 \mathrm{~ns}$ & 28.8 & 20207 & 8.24 \\
\hline Otilia, Romania & 131 & $93.2^{* * *(-)}$ & 706 & $37.6^{\star * *(-)}$ & 31.3 & $21894^{* *}$ & 8.23 \\
\hline Nota, Russia & 133 & $81.8^{* * *(-)}$ & $863^{* *}$ & $40.1 \mathrm{~ns}$ & 23.9 & 20335 & 8.15 \\
\hline GK Vitorlas, Hungary & 133 & $94.7^{* * *(-)}$ & 668 & $36.1^{* * *(-)}$ & $33.5^{*}$ & $22570^{* *}$ & 8.15 \\
\hline Faur, Romania & 131 & $91.5^{\star * *(-)}$ & 620 & $39.5^{* *(-)}$ & $33.4^{*}$ & 20591 & 8.14 \\
\hline F02870G2-101, Romania & 130 & $94.2^{* * *(-)}$ & 727 & $41.2^{\text {ns }}$ & 27.8 & 19669 & 8.1 \\
\hline Goritsa, Bulgaria & 131 & $95.7^{* * *(-)}$ & 673 & $35.9^{* * *(-)}$ & $32.8^{*}$ & $22399^{* *}$ & 8.04 \\
\hline Mean Standard & 130 & 104.1 & 652 & 41.3 & 26.7 & 17695 & 7.27 \\
\hline Standard Deviation & 2.36 & 7 & 67 & 2.5 & 3.2 & 1600 & 0.38 \\
\hline VC \% & $1.81 \%$ & $7.37 \%$ & $9.57 \%$ & $6.34 \%$ & $10.47 \%$ & $7.50 \%$ & $4.54 \%$ \\
\hline
\end{tabular}

$*_{-} \mathrm{P}<0.05 * *_{-} \mathrm{P}<0.01 * * *_{-} \mathrm{P}<0.001$ ns - non significant $(-)$ - below standard

as sources of variation which had revealed significant GY differences from the mean check for PKB Vizelika, PKB Rodika, Joana, Midas and Azimut. The trait NGM shows strong effect on GY for high yielding accessions, with $65 \%$ of the cultivars significantly above the mean check. Varieties PKB Vizelika, PKB Rodika exceed standard with NGS which was the main reason for high NGM and consequently GY. Variety Joana exceeded the standard group with higher TKW and despite insignificant increase in NPT and NGS, the combined effect adds up to significant NGM which may have led to significant GY increase. Varieties Midas and Azimut have produced more spikes on $\mathrm{m}^{2}$ but had fewer grains. Despite this fact, NGM remain high and this may have led to higher yield. Stem height was significantly below the mean standard in $80 \%$ of the high yielding accessions which suggests that semi-dwarf genotypes are more successful. Finally, genotypes of different origin can achieve high yield in environments of South Dobruzha. All European varieties show high yield potential, which is a result of breeding efforts to reduce the trade-off between traits, on the one hand, and retain compensatory potential between them, on the other. Same as with local varieties, main yield components TKW and NGS show direct effect on yield of all accessions (Tsenov et al., 2009; Tsenov et al., 2014). Although NPT shows no effect on GY directly, it has significant effect on NGM which shows its importance. Same as with Bulgarian cultivars, foreign varieties possess a combination of desirable traits which is evident enough to be successfully included in future breeding programs to widen genotypic variability and increase productivity of the local biotype.

\section{Conclusion}

Agrater gain in grain yield in the tested 118 varieties and lines of winter wheat is associated with moderation of all investigated traits. 
For all investigated traits a conditioning genetic modality is found in spite of the significant effect of the growing environment. The established regularities are a prerequisite for involving a large number of these accessions in the breeding program to guarantee high level of productivity in the crosses with them. The investigated accessions present wide range of trait combinations which can be used in breeding to improve the wheat plant in the future.

\section{References}

Aliu S and Fetahu S, 2010. Determination on Genetic Variation for Morphological Traits and Yield Components of New Winter Wheat (Triticum aestivum L.) Lines. Notulae Scientia Biologicae 2.1, 121124.

Bustos DV, Hasan AK, Reynolds MP and Calderini DF, 2013. Combining high grain number and weight through a $\mathrm{DH}$-population to improve grain yield potential of wheat in high-yielding environments. Field Crops Research, 145, 106-115.

Chen H, Martin J, Lavin M and Talbert L, 1994. Genetic diversity in hard red spring wheat based on sequence-tagged-site PCR markers. Crop Science, 34, 1628-1632.

Donmez E, Sears RG, Shroyer JP and Paulsen GM, 2001. Genetic gain in yield attributes of winter wheat in the Great Plains. Crop Science, 41, 1412-1419.

Huang XQ, Wolf M, Ganal MW, Orford S, Koebner R and Röder MS, 2007. Did modern plant breeding lead to genetic erosion in European winter wheat varieties? Crop Science, 47, 343-349.

Okuyama LA, Federizzi LC and Barbosa Neto JF, 2004. Correlation and path analysis of yield and its components and plant traits in wheat. Ciência Rural, 34, 1701-1708.

Reynolds M, Foulkes MJ, Slafer GA, Berry P, Parry MA, Snape
JW and Angus WJ, 2009. Raising yield potential in wheat. Journal of Experimental Botany, 60, 1899-1918.

Sanchez-Garcia M, Royo C, Aparicio N, Martín-Sánchez JA and Alvaro F, 2013. Genetic improvement of bread wheat yield and associated traits in Spain during the 20th century. The Journal of Agricultural Science, 151, 105-118.

Slafer G, Savin R and Sandras V, 2014. Coarse and fine regulation of wheat yield components in response to genotype and environment. Field Crop Research, 157, 71-83.

Stoeva I, Chamurliyski P and Tsenov N, 2009. Investigation on Bulgarian and foreign common winter wheat cultivars and lines in relation to their use in breeding for productivity and quality. Field Crops Studies, 5, 253-260 (Bg).

Tsenov N, Kostov K, Todorov I, Panayotov I, Stoeva I, Atanassova D, Mankovsky I and Chamurliysky P, 2009. Problems, achievements and prospects in breeding for grain productivity of winter wheat. Field Crop Studies, 5, 261-273 (Bg).

Tsenov N, Atanasova D and Gubatov T, 2013. Genotype x environment effects on the productivity traits of common wheat. I. Nature of the interaction. Research communications of the Institute of Agriculture, Karnobat 2, 57-70 (Bg).

Tsenov N, Gubatov T, Atanasova D, Nankova M and Ivanova A, 2014. Genotype x Environment Effects on The Productivity Traits of Common Wheat (Triticum aestivum L.) II. Analysis of Genotype Reaction. Turkish Journal of Agricultural and Natural Sciences, Balkan Agriculture Congress, Special Issue 1, 1198-1208.

Zhou Y, He ZH, Sui XX, Xia XC, Zhang XK and Zhang GS, 2007. Genetic improvement of grain yield and associated traits in the northern China winter wheat region from 1960 to 2000. Crop Science, 47, 245-253.

Zobel RW, Wright MJ and Gauch HG, 1988. Statistical analysis of a yield trial. Agronomy Journal, 80, 388-393. 
Review

Triticale-past and future

St. Dobreva

\section{Genetics and Breeding}

Productivity performance of bread winter wheat genotypes with local and foreign origin

G. Raykov, P. Chamurliyski, S. Doneva, E. Penchev, N. Tsenov

Production properties of flax (Linum usitatissimum L.) cultivated in Strumica region, Republic of Macedonia

P. Vuckov, M. llievski, D. Spasova, L. Mihajlov, N. Markova-Ruzdić

Quality of grain and flour of foreign bread wheat cultivars (Triticum aestivum L.) under the conditions of south Dobrudzha region

P. Chamurliyski, N. Tsenov, I. Stoeva, S. Doneva, E. Penchev

Breeding programme for developing new sweet cherry cultivars in the Fruit Growing Institute,

Plovdiv, Bulgaria

S. Malchev, A. Zhivondov

Heterosis manifestations by survival and larval duration of F1 Bombyx mori L. hybrids

R. Guncheva, M. Panayotov, P. Tsenov, Y. Dimitrova

\section{Nutrition and Physiology}

Reproductive performance of breeding rabbits fed by graded levels of cassava (Manihot esculenta) leaf meal

T. Ahemen, I.I. Bitto, O.I.A. Oluremi

Clinical toxicological investigations on acute carbofuran intoxication in quails (Coturnix coturnix)

R. Binev, I. Valchev, R. Mihaylov, Y. Nlkolov

\section{Production Systems}

Efficacy and timing of some new products against pear psylla (Cacopsylla pyri L.) (Hemiptera:

Psyllidae): II. Spirodiclofen

V. Arnaudov

Biochemical and chemical investigations of pikeperch fingerlings (Sander Lucioperca L.) after wintering
A. Ivanova, R. Atanasova 
Effect of fluorescence on the technological characteristics of cocoons at different cooking temperatures

M. Panayotov

Comparative analysis of spatial planning parameters of various types of cow milking parlors

D. Georgiev

Agriculture and Environment

Panthaleus major/Duges/ of cereals in Bulgaria

V. Maneva, D. Atanasova

Selectivity and stability of herbicides and their tank mixtures for the seed yield of sunflower (Helianthus Annuus L.)

G. Delchev, T. Barakova

Effect of green manure cover crops on tomato greenhouse production

I. Tringovska, V. Yankova, D. Markova

Reclamation of lands disturbed by mining activities in Bulgaria

I. Kirilov, M. Banov

Product Quality and Safety

Fish production and meat quality traits in rainbow trout (Oncorhynchus mykiss) farmed in different production systems

St. Stoyanova, Y. Staykov, G. Zelqzkov, I. Sirakov, G. Nikolov 


\section{Instruction for authors}

\section{Preparation of papers}

Papers shall be submitted at the editorial office typed on standard typing pages (A4, 30 lines per page, 62 characters per line). The editors recommend up to 15 pages for full research paper ( including abstract references, tables, figures and other appendices)

The manuscript should be structured as follows: Title, Names of authors and affiliation address, Abstract, List of keywords, Introduction, Material and methods, Results, Discussion, Conclusion, Acknowledgements (if any), References, Tables, Figures.

The title needs to be as concise and informative about the nature of research. It should be written with small letter /bold, 14/ without any abbreviations.

Names and affiliation of authors The names of the authors should be presented from the initials of first names followed by the family names. The complete address and name of the institution should be stated next. The affiliation of authors are designated by different signs. For the author who is going to be corresponding by the editorial board and readers, an E-mail address and telephone number should be presented as footnote on the first page. Corresponding author is indicated with *.

Abstract should be not more than 350 words. It should be clearly stated what new findings have been made in the course of research. Abbreviations and references to authors are inadmissible in the summary. It should be understandable without having read the paper and should be in one paragraph.

Keywords: Up to maximum of 5 keywords should be selected not repeating the title but giving the essence of study.

The introduction must answer the following questions: What is known and what is new on the studied issue? What necessitated the research problem, described in the paper? What is your hypothesis and goal?

Material and methods: The objects of research, organization of experiments, chemical analyses, statistical and other methods and conditions applied for the experiments should be described in detail. A criterion of sufficient information is to be possible for others to repeat the experiment in order to verify results.

Results are presented in understandable tables and figures, accompanied by the statistical parameters needed for the evaluation. Data from tables and figures should not be repeated in the text. Tables should be as simple and as few as possible. Each table should have its own explanatory title and to be typed on a separate page. They should be outside the main body of the text and an indication should be given where it should be inserted.

Figures should be sharp with good contrast and rendition. Graphic materials should be preferred. Photographs to be appropriate for printing. Illustrations are supplied in colour as an exception after special agreement with the editorial board and possible payment of extra costs. The figures are to be each in a single file and their location should be given within the text.

Discussion: The objective of this section is to indicate the scientific significance of the study. By comparing the results and conclusions of other scientists the contribution of the study for expanding or modifying existing knowledge is pointed out clearly and convincingly to the reader. Conclusion: The most important consequences for the science and practice resulting from the conducted research should be summarized in a few sentences. The conclusions shouldn't be numbered and no new paragraphs be used. Contributions are the core of conclusions. References:

In the text, references should be cited as follows: single author: Sandberg (2002); two authors: Andersson and Georges (2004); more than two authors: Andersson et al.(2003). When several references are cited simultaneously, they should be ranked by chronological order e.g.: (Sandberg, 2002; Andersson et al., 2003; Andersson and Georges, 2004).

References are arranged alphabetically by the name of the first author. If an author is cited more than once, first his individual publications are given ranked by year, then come publications with one co-author, two co-authors, etc. The names of authors, article and journal titles in the Cyrillic or alphabet different from Latin, should be transliterated into Latin and article titles should be translated into English. The original language of articles and books translated into English is indicated in parenthesis after the bibliographic reference $($ Bulgarian $=\mathrm{Bg}$, Russian $=\mathrm{Ru}$, Serbian $=\mathrm{Sr}$, if in the Cyrillic, Mongolian =
Mo, Greek = Gr, Georgian = Geor., Japanese $=\mathrm{Ja}$, Chinese $=\mathrm{Ch}$, Arabic $=\mathrm{Ar}$, etc.)

The following order in the reference list is recommended:

Journal articles: Author(s) surname and initials, year. Title. Full title of the journal, volume, pages. Example:

Simm G, Lewis RM, Grundy B and Dingwall WS, 2002. Responses to selection for lean growth in sheep. Animal Science, 74, 39-50

Books: Author(s) surname and initials, year. Title. Edition, name of publisher, place of publication. Example:

Oldenbroek JK, 1999. Genebanks and the conservation of farm animal genetic resources, Second edition. DLO Institute for Animal Science and Health, Netherlands.

Book chapter or conference proceedings: Author(s) surname and initials, year. Title. In: Title of the book or of the proceedings followed by the editor(s), volume, pages. Name of publisher, place of publication. Example:

Mauff G, Pulverer G, Operkuch W, Hummel K and Hidden C, 1995. C3variants and diverse phenotypes of unconverted and converted C3. In: Provides of the Biological Fluids (ed. $\mathrm{H}$. Peters), vol. 22, 143-165, Pergamon Press. Oxford, UK.

Todorov N and Mitev J, 1995. Effect of level of feeding during dry period, and body condition score on reproductive performance in dairy cows, $I^{\text {th }}$ International Conference on Production Diseases in Farm Animals, September 11-14, Berlin, Germany.

Thesis:

Hristova D, 2013. Investigation on genetic diversity in local sheep breeds using DNA markers. Thesis for PhD, Trakia University, Stara Zagora, Bulgaria, (Bg).

The Editorial Board of the Journal is not responsible for incorrect quotes of reference sources and the relevant violations of copyrights.

\section{Animal welfare}

Studies performed on experimental animals should be carried out according to internationally recognized guidelines for animal welfare. That should be clearly described in the respective section "Material and methods". 


\section{AGRICULTURAL \\ SCIENCE AND TECHNOLOGY}

Volume 8, Number 4

December 2016
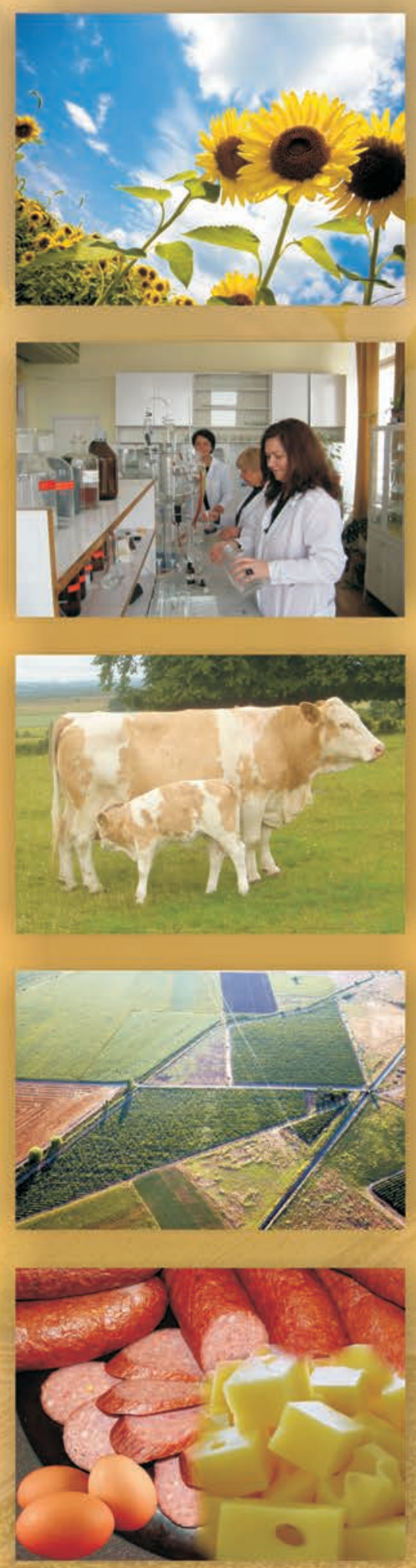

Journal web site: 